\section{Lupeol Isolated from Betula alnoides Ameliorates Amyloid Beta Induced Neuronal Damage via Targeting Various Pathological Events and Alteration in Neurotransmitter Levels in Rat's Brain}

\section{Abstract}

Lupeol, a natural active constituent of Betula alnoides (BA), is well known for its anti-inflammatory, anti-oxidant and neuroprotective activities. In present study the therapeutic potential of lupeol was investigated against amyloid beta $\left(A \beta_{(1-42)}\right)$ induced cognitive deficit, neurochemical and biochemical abnormalities in rats. Lupeol was isolated from the $B A$ and its structure was confirmed through nuclear magnetic resonance spectra. $A \beta_{(1-42)}(4 \mu \mathrm{g} / 4 \mu \mathrm{L})$ intracerebroventrically (icv) was administered to rats for the induction of Alzheimer's disease (AD). Lupeol treatment $(25 \mathrm{mg} / \mathrm{kg} /$ day, $50 \mathrm{mg} / \mathrm{kg} /$ day and $100 \mathrm{mg} / \mathrm{kg} /$ day per orally) was started one week after $A \beta_{(1-42)}$ infusion up to the $21^{\text {st }}$ days. Morris water maze from day 16 to 21 and object recognition tasks on day 14 and 15 were performed for memory assessment. On $22^{\text {nd }}$ day, animals were sacrificed and hippocampi were isolated for analysis of biochemical (acetylcholinesterase, lipid hydroperoxide, glutathione and nitrite) and neuro-inflammatory (tumor necrosis factor $-\alpha$, interleukin (IL)-1 $\beta$, and IL-6) parameters. In the present study $A \beta_{(1-42)}$ infusion was significantly impaired behavioral memory, increased oxidative stress, decreased antioxidant enzyme and increased pro-inflammatory markers. Treatment of lupeol significantly restored $A \beta_{(1-42)}$ induced behavioral and biochemical abnormalities in rats brain. The findings of the present study suggest that lupeol act through multiple mechanisms and would be used to curb cognitive decline associated with neurodegenerative disorders of $A D$.

Keywords: Alzheimer's disease; Lupeol; Memory; Cognitive disorder; Oxidative stress

\author{
Madhu Kaundal', \\ Mohd Akhtar ${ }^{1}$ and \\ Rahul Deshmukh²
1 Department of Pharmacology, Faculty of Pharmacy, Jamia Hamdard (Hamdard University), New Delhi-110062, India 2 Pharmacology Division, ISF College of Pharmacy, Moga (Punjab), India

Corresponding author: Madhu Kaundal

” madhukaundal07@gmail.com

Doctoral Research Fellow, Department of Pharmacology, Faculty of Pharmacy, Jamia Hamdard (Hamdard University), New Delhi-110062, India.

Tel: $+91-8557082640$

Citation: Kaundal M, Akhtar M, Deshmukh R. Lupeol Isolated from Betula alnoides Ameliorates Amyloid Beta Induced Neuronal Damage via Targeting Various Pathological Events and Alteration in Neurotransmitter Levels in Rat's Brain. J Neurol Neurosci. 2017, 8:3.

\section{Introduction}

Alzheimer's disease (AD) is the most common form of dementia characterized by extracellular deposits of amyloid beta ( $A \beta$ (1-42)), intracellular neuro-fibrillary tau tangle, oxidative stress and decline in cognitive functions [1-3]. Although the exact pathogenic mechanisms remain unclear, transcriptional dysregulation and impaired cyclic nucleotide signaling have been reported in experimental animals as well as in AD patients [46]. Recent neuropathological studies have also established a link between morphological and functional changes occurring in the monoaminergic ascending system, particularly in nor epinephrine (NE) and 5-hydroxytriptamine (5-HT), and the pathophysiology of AD. Moreover clinical researchers found that $A D$ patients have complex neurochemical disturbances including the catecholaminergic, cholinergic and glutaminergic neuronal systems [7-10].

Lupeol, a biologically active dietary triterpenoid is found in many medicinal plants and different fruits such as olives, mangoes, and strawberries [11,12]. A variety of medicinal plants such as Betula alnoides, Vernonanthura ferruginea and Zanthoxylum rhoifolium have also been reported to contain lupeol as an active constituent [13-15]. Lupeol has been reported to have various pharmacological activities including acetylcholinesterase (AChE) 
inhibition, anti-inflammatory and anti-oxidant actions [16-18]. Further, it has been reported to be effective in various pathologies and recently its neuroprotective effect has been studied $[19,20]$. Indeed Brimson et al. [21] described a neuroprotective effect of lupeol against glutamate-induced neurotoxicity in HT22 mouse hippocampal cells.

Intra-cerebroventricular (ICV) administration of $A \beta_{(1-42)}$ is a well-known model to produce behavioral, biochemical and neuropathological changes similar to that seen in clinical $A D$ and considered as an appropriate animal model of AD [22]. Thus, the present work was carried out to investigate the neuroprotective potential of lupeol against ICV-A $\beta_{(1-42)}$ induced cognitive impairment, neurotransmitters deficits, neuroinflammation and oxidative-nitrosative stress in rats.

\section{Material and Methods}

\section{Drugs and chemicals}

The stem bark of Betula alnoides $(B A)$ was collected from the mountains of Himachal Pradesh, INDIA. The plant $B A$, was identified by Dr. H.B. Singh, an eminent botanist (Ref. No.NISCAIR/ RHMD/ CONSULT/ 2014/ 2398-178) of NISCAIR, New Delhi, India. $A \beta_{(1-42)}$ was purchased from Sigma-Aldrich, USA. All other chemicals used in the study were of analytical grade. Solutions of the drugs and chemicals were always prepared afresh before use.

\section{Extraction and fractionation of BA (Stem bark)}

$50 \mathrm{gm}$ of dried and powdered bark of $B A$ was soxhlated with ethanol $\left(60^{\circ} \mathrm{C}\right.$ to $\left.80^{\circ} \mathrm{C}\right)$ yielding $14.6 \mathrm{~g}$ of dry ethanolic extract. Lupeol, as a major constituent was separated out using a column chromatography technique [23]. Different spectroscopic methods were used to elucidate the structure of lupeol using Fourier transform infrared spectroscopy (FTIR) -Nicolet S10 (Thermospecific) in $\mathrm{CCl}_{4}$ at I.S.F. Analytical Lab, Moga. Nuclear magnetic resonance (NMR) spectra were recorded on a Bruker AVANCE-400 Japan (100 MHz and $400 \mathrm{MHz}$ ) in chloroform with tetramethylsilane as internal standard at the SAIF, Punjab University, Chandigarh, India.

\section{Animals}

Male wistar rats (250-300 g) were obtained from Central Animal House of I.S.F. College of Pharmacy, Moga, Punjab (India). Animals were kept in polyacrylic cages (4/cage) and maintained under standard husbandry conditions (room temperature $22 \pm$ $1^{\circ} \mathrm{C}$ and relative humidity of $60 \%$ ) with a $12 \mathrm{~h}$ light/dark cycle (lights on at $8 \mathrm{AM}$ ). The protocol was reviewed and approved by the Institutional Animal Ethics Committee and the experiments were carried out according to Indian National Science Academy guidelines.

\section{Experimental procedure}

Animals were anesthetized with ketamine $(100 \mathrm{mg} / \mathrm{kg}$, i.p) and xylazine (5 mg/kg, i.p) and were fixed on steriotaxic apparatus. Skull was exposed after midline sagittal incision and holes on both sides of the brain were drilled according to Paxinos and
Watson [24]. Animals were divided into five groups and each group comprised of 10 animals. The treatment schedule and the interval for estimation of various parameters were described as; Group1: served as double vehicle control, received artificial cerebrospinal fluid (ACSF) in a volume of $4 \mu \mathrm{l}$ in each ventricle on day $1 \%$ and $2 \%$ dimethyl sulfoxide per orally (p.o., as a vehicle of lupeol) for 21 days. Group 2: Rats were infused with ICV-A $\beta_{(1-42)}(4$ $\mu \mathrm{g} / 4 \mu \mathrm{L}$ ) dissolved in ACSF in a volume of $4 \mu \mathrm{l}$ in each ventricle on day 1. Group 3, 4 and 5 received lupeol at doses of $25 \mathrm{mg} / \mathrm{kg}, 50$ $\mathrm{mg} / \mathrm{kg}, 100 \mathrm{mg} / \mathrm{kg}$ p.o. respectively 1 week after the ICV-A $\beta_{(1-42)}$ infusion starting from day 7 and continued once daily at $10 \mathrm{am}$ daily for a period of 21 days. The doses of lupeol were selected on the basis of earlier reports in which significant antioxidant and neuroprotective properties were demonstrated $[18,25]$.

Object Recognition test (ORT): The ORT was performed as described by Giorgetti et al. [26].

Spatial navigation task: Spatial learning and memory of animals in a Morris water maze (MWM) was tested by the method described by Morris [27].

Brain homogenate preparation: Terminally, on day 22, rats were sacrificed and hippocampus from the brain was separated, weighed and then homogenized individually. The various biochemical parameters were determined separately in hippocampal supernatant collected following homogenization. Animals were perfused with phosphate buffer saline before decapitation from the heart to remove blood from the brain tissues completely and its interference with the homogenate readouts. After perfusion, animals were sacrificed by decapitation and brains were removed and rinsed with ice-cold isotonic saline. The rat hippocampal tissues were then homogenized with ice cold $0.1 \mathrm{M}$ phosphate buffer ( $\mathrm{pH} 7.4)$ in a volume 10 times the weight of the tissue. The homogenate was centrifuged at 10,000 g for $15 \mathrm{~min}$ $\left(4^{\circ} \mathrm{C}\right)$ and aliquots of supernatant were separated and used for biochemical analysis. Protein was measured in all brain samples by the method of Lowry et al. [28] using bovine serum albumin (1 $\mathrm{mg} / \mathrm{ml}$ ) as a standard.

AChE activity: The quantitative measurement of AChE activity in brain was performed according to the method described by Ellman et al. [29].

Malondialdehyde (MDA) estimation: The quantitative measurement of MDA end product of lipid peroxidation-in brain homogenate was performed according to the method of Wills [30].

Nitrite estimation: The accumulation of nitrite in the supernatant, an indicator of the production of nitric oxide was determined by a colorimetric assay using Greiss reagent $(0.1 \% \mathrm{~N}$-[1naphthyl] ethylene diaminedihydro chloride, $1 \%$ sulfanilamide and $2.5 \%$ phosphoric acid) as described by Green et al. [31].

Reduced glutathione (GSH) estimation: GSH in hippocampus was estimated according to the method described by Ellman [32].

Pro-inflammatory cytokines such as tumor necrosis factor $-\alpha$ (TNF- $\alpha$ ), interleukin (IL)-1 $\beta$ and IL- 6 estimation: The quantifications of TNF- $\alpha$, IL- 6 , and IL- $1 \beta$ were done by rat TNF- $\alpha$, IL- 6 , and IL-1 $\beta$ immunoassay kit (KRISHGEN BioSystem, Ashley Ct, Whitti- 
er, CA). Concentrations of TNF- $\alpha$, IL- 6 , and IL- $1 \beta$ were calculated from the plotted standard curves [33].

\section{Statistical analysis}

The values were expressed as mean \pm standard error mean (SEM). $\mathrm{P}<0.05$ was set to be statistically significant. The results were analyzed using Analysis of variance using statistical Graph Pad Prism software. In ORT, time of exploration during T1 and $\mathrm{T} 2$ on familiar and novel object was analyzed by paired student t-test.

\section{Results}

\section{Isolation of lupeol}

The melting point of the compound, lupeol was found to be $213^{\circ} \mathrm{C}$ to $215^{\circ} \mathrm{C}$. The FTIR spectra gave information about the functional groups or chemical entities present in lupeol which was found in accordance with the literature data of lupeol [33]. Further $1 \mathrm{H}$ NMR spectrum of the compound revealed the presence of seven tertiary methyl protons, a sextet of one proton at $\delta 2.17$ and presence of olefinic protons at ( $\mathrm{H}-29 \mathrm{a}$ and $\mathrm{b})$ which is characteristic of lupeol [34]. On the basis of FTIR and NMR spectra structure of compound was drawn which was in good conformity for the structure of lupeol (Figure 1).

\section{Effect of lupeol on memory performance in MWM task of ICV-A 3 (1-42)-infused rats}

In the MWM, animals were trained for 5 days starts on day 17 of $A \beta_{(1-42)}$-infusion. On day 17 ( $1^{\text {st }}$ trial), there was no significant difference between the mean latencies of all groups. $A \beta$ (1-42) -infused animal showed poor ability (increased latency to find the platform) to learn the task on days 18,19 and 20 as compared to control group. On $21^{\text {st }}$ day the time spent in the target quadrant were also significantly decreased in $A \beta_{(1-42)}$-infused animal as compared to control group (Figure 2A). $A \beta_{(1-42)}$-infused rats failed to remember the precise location of the platform, spent significantly less time in the target quadrant as compared with control group (Figure 2B). Whereas pretreatment with lupeol $(25,50$ and $100 \mathrm{mg} / \mathrm{kg})$ significantly attenuated $A \beta_{(1-42)}$-induced acquisition deficit and showed a significant difference between the mean latencies.

\section{Effect of lupeol on non-spatial memory performance in ORT in ICV- $A \beta$ (1-42)-infused rats}

There was no significant difference observed between the $A \beta$ $(1-42)$-infused and Lupeol-treated rats for familiar objects (Figure 3A). When $A \beta_{(1-42)}$ infused rats were exposed to familiar and novel objects in ORT, they were unable to discriminate between familiar and novel objects and spend almost equal time to explore the similar and novel objects as compared to control group (Figure 3B). Whereas, lupeol $(25 \mathrm{mg} / \mathrm{kg}, 50 \mathrm{mg} / \mathrm{kg}$ and

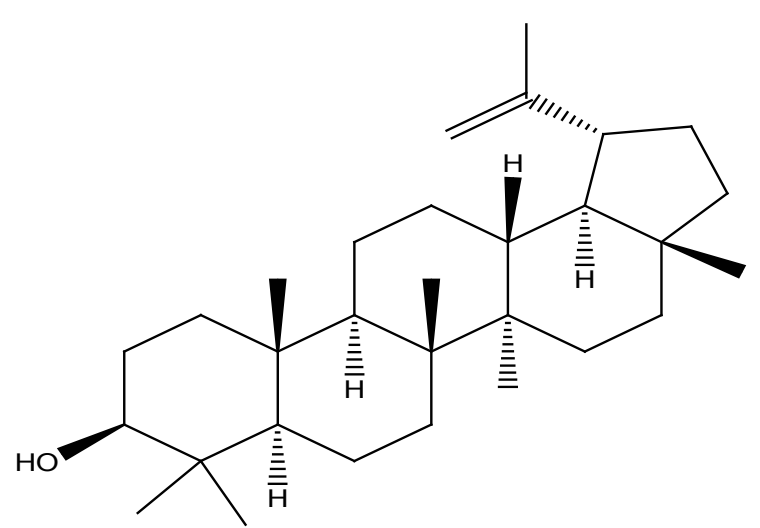

Figure 1 Chemical structure of lupeol.

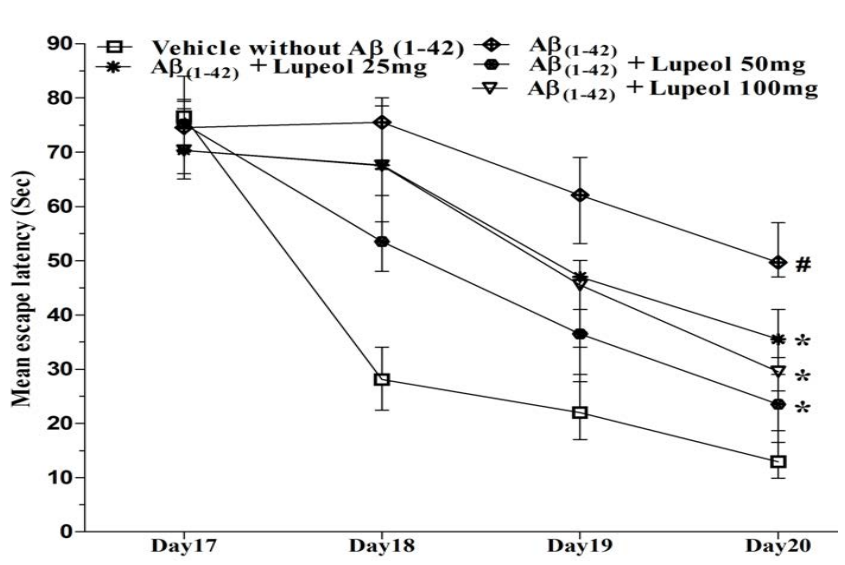

Figure 2A Effect of lupeol on MWM performance (mean escape latency) in $A \beta_{(1-42)}$ infused rats. The values are expressed as mean \pm SEM $(n=10)$. (A \& B) ${ }^{\#} P<0.001$ vs. vehicle, ${ }^{*} P<0.05$ vs. $A \beta_{(1-42)}$.

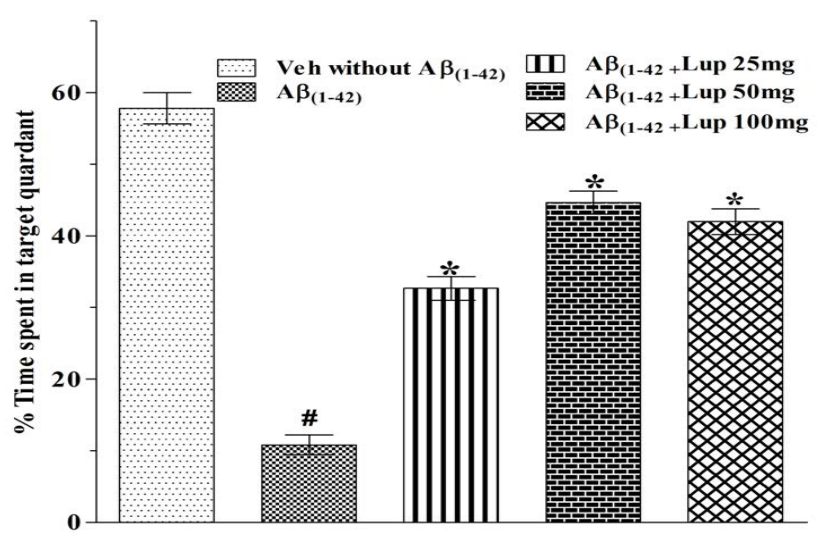

Figure 2B

Effect of lupeol on MWM performance (time spend in target quadrant) in $A \beta_{(1-42)}$ infused rats. The values are expressed as mean $\pm \operatorname{SEM}(n=10)$. (A \& B) ${ }^{\#} P<0.001$ vs. vehicle, ${ }^{*} P<0.05$ vs. $A \beta_{(1-42)}$. 
$100 \mathrm{mg} / \mathrm{kg}$ ) treatment produced significant improvement in discriminating ability between familiar and novel object in $A \beta_{(1-42)}$ infused rats (Figure $\mathbf{3 C}$ ).

\section{Effect of lupeol on $A C h E$ activity in $A \beta$ (1-42)-infused rats}

ICV infusion of $A \beta_{(1-42)}$ produced significant increase in $A C h E$ activity as compared with vehicle treated groups. Lupeol (25 $\mathrm{mg} / \mathrm{kg}, 50 \mathrm{mg} / \mathrm{kg}$ and $100 \mathrm{mg} / \mathrm{kg}$ ) attenuated $A \beta_{(1-42)}$-induced elevation in AChE activity (Figure 4 ) and restored the values as that of vehicle control rats.

\section{Effect of lupeol treatment on brain oxidative- nitrosative stress (MDA, GSH and nitrite) levels in ICV-A $\beta_{(1-42)}$ injected rats}

The level of MDA and nitrite were increased and GSH was decreased significantly in $A \beta_{(1-42)}$ infused groups as compared of control group. Lupeol ( $25 \mathrm{mg} / \mathrm{kg}, 50 \mathrm{mg} / \mathrm{kg}$ and $100 \mathrm{mg} / \mathrm{kg}$ ) treatment significantly restored the MDA, nitrite and GSH levels as compared with those of $A \beta_{(1-42)}$-infused rats (Table 1).

\section{Effect of lupeol treatment on brain pro- inflammatory cytokines levels in ICV-A $\beta$ (1-42)-infused rats}

The levels of TNF- $\alpha$, IL- 6 and IL- $1 \beta$ were increased significantly in hippocampus following $A \beta_{(1-42)}$ infusion as compared with control group. Lupeol $(25 \mathrm{mg} / \mathrm{kg}, 50 \mathrm{mg} / \mathrm{kg}$ and $100 \mathrm{mg} / \mathrm{kg}$ ) treatment significantly restored the hippocampal pro-inflammatory cytokines level as compared with $A \beta_{(1-42)}$ infused rats (Table 2).

\section{Discussion}

The present study demonstrates the neuroprotective potential of lupeol against $A \beta_{(1-42)}$ induced behavioral, biochemical and neurochemical abnormalities in rats. ICV infusion of $A \beta_{(1-42)}$ in rats is known to produce cognitive deficit and other neuropathological changes similar to those seen in $A D$ and thus considered as

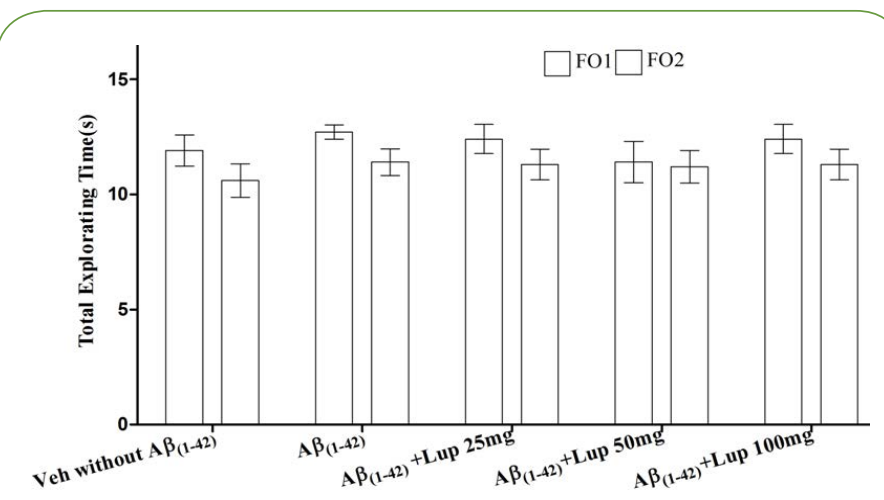

Figure 3A Effect of lupeol in ORT in $A \beta_{(1-42)}$ infused rats. The values are expressed as mean \pm SEM $(n=10)$. (A) The performance of rats in (T1) sample phase trial with two similar objects (F01 and F02). No significant difference was observed between the untreated and Lupeol-treated rats.
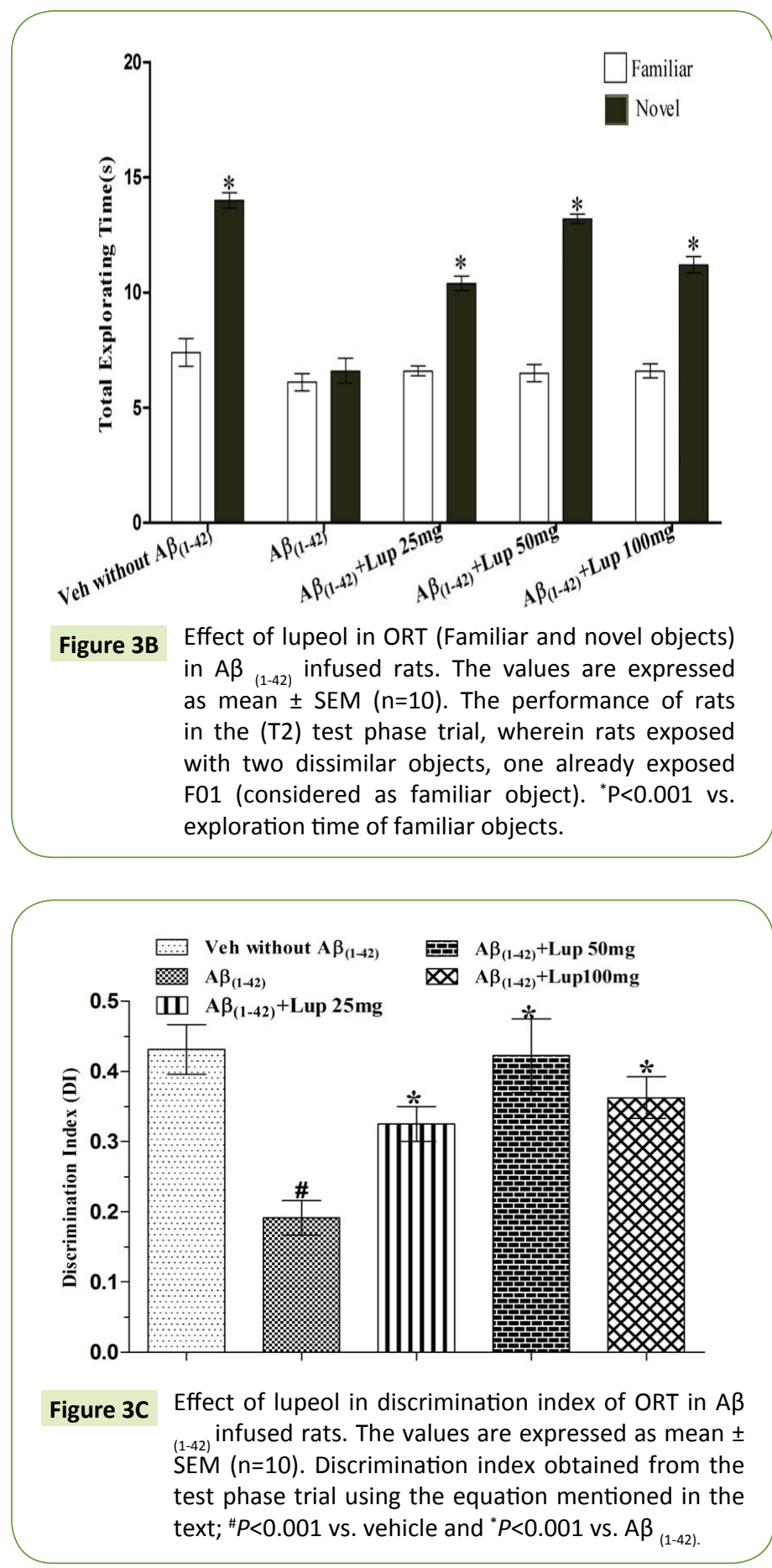

a suitable model system of $A D[23,35]$. In the present study, ICV-A $\beta_{(1-42)}$ infusion produced cognitive impairment, oxidative stress, neuroinflammation and hippocampal neurotransmitter deficit demonstrating similar changes following $A \beta_{(1-42)}$ infusion in rats [35]. $A \beta_{(1-42)}$ is an oligomer, reported to cause destruction in the selective brain regions such as hippocampus, cortex and perirhinal cortex that affects spatial and non-spatial memory respectively [36-38]. MWM and ORT were used to assess spatial and non-spatial memory respectively. In the present study, $A \beta_{(1-42)}$ infused rat showed poor learning and consolidation of memory in MWM task. In addition, these animals were unable to discriminate between novel and familial objects indicating 


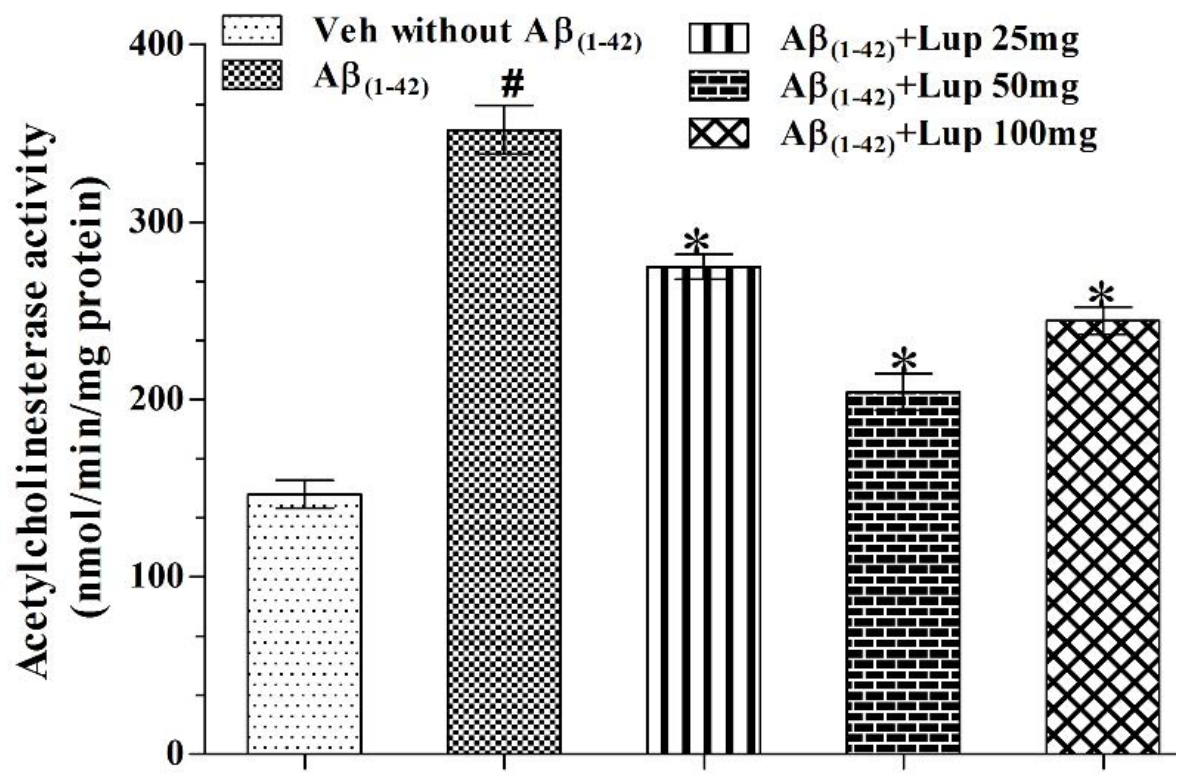

Figure 4 Effect of lupeol on $A C h E$ activity in $A \beta_{(1-42)}$ infused rats. The values are expressed as mean \pm SEM ( $n=10) . "{ }^{\#}<0.001$ vs. Vehicle; ${ }^{*} P<0.001$ vs. $A \beta_{(1-42)}$.

Table 1 Effect of lupeol on rat hippocampal oxidative-nitrosative stress parameters in $A \beta_{(1-42)}$-infused rats.

\begin{tabular}{|c|c|c|c|}
\hline \multirow{2}{*}{ Groups } & \multicolumn{3}{|c|}{ Biochemical Parameters } \\
\hline & Nitrite ( $\mu \mathrm{mol} / \mathrm{mg}$ protein) & MDA (nmol/mg protein) & GSH ( $\mu \mathrm{mol} / \mathrm{mg}$ protein) \\
\hline Vehicle without $A \beta_{(1-42)}$ & $85.8 \pm 08.63$ & $1.075 \pm 0.344$ & $0.950 \pm 0.051$ \\
\hline$A \beta_{(1-42)}$ & $208.6 \pm 16.92^{\#}$ & $5.213 \pm 0.143^{\#}$ & $0.175 \pm 0.040^{\#}$ \\
\hline$A \beta_{(1-42)}+$ Lupeol $25 \mathrm{mg}$ & $178.9 \pm 15.87^{*}$ & $3.813 \pm 0.591^{*}$ & $0.485 \pm 0.034^{*}$ \\
\hline $\mathrm{A} \beta_{(1-42)}+$ Lupeol $50 \mathrm{mg}$ & $139.0 \pm 14.88^{*}$ & $2.913 \pm 0.779^{*}$ & $0.625 \pm 0.043^{*}$ \\
\hline$A \beta_{(1-42)}+$ Lupeol $100 \mathrm{mg}$ & $148.9 \pm 19.37^{*}$ & $3.313 \pm 0.591^{*}$ & $0.535 \pm 0.034^{*}$ \\
\hline
\end{tabular}

Table 2 Effect of lupeol on rat hippocampal TNF-a, IL-6, and IL-1b levels in $A \beta_{(1-42)}$ rats.

\begin{tabular}{|c|c|c|c|}
\hline \multirow{2}{*}{ Groups } & \multicolumn{3}{|c|}{ Biochemical Parameters } \\
\hline & TNF $\alpha(p g / m l)$ & IL-1 $\beta$ (pg/ml) & IL-6 (pg/ml) \\
\hline Vehicle without $A \beta_{(1-42)}$ & $43.31 \pm 6.717$ & $26.10 \pm 4.990$ & $22.17 \pm 0.799$ \\
\hline$A \beta_{(1-42)}$ & $107.20 \pm 9.058^{\#}$ & $88.10 \pm 8.751^{\#}$ & $71.15 \pm 7.751^{\#}$ \\
\hline$A \beta_{(1-42)}+$ Lupeol $25 \mathrm{mg}$ & $81.11 \pm 6.072^{*}$ & $62.16 \pm 4.930^{*}$ & $56.80 \pm 7.930^{*}$ \\
\hline$A \beta_{(1-42)}+$ Lupeol $50 \mathrm{mg}$ & $68.79 \pm 6.820^{*}$ & $51.93 \pm 6.085^{*}$ & $39.46 \pm 6.085^{*}$ \\
\hline$A \beta_{(1-42)}+$ Lupeol $100 \mathrm{mg}$ & $74.41 \pm 8.392^{*}$ & $57.96 \pm 5.930^{*}$ & $47.80 \pm 7.930^{*}$ \\
\hline \multicolumn{4}{|c|}{ 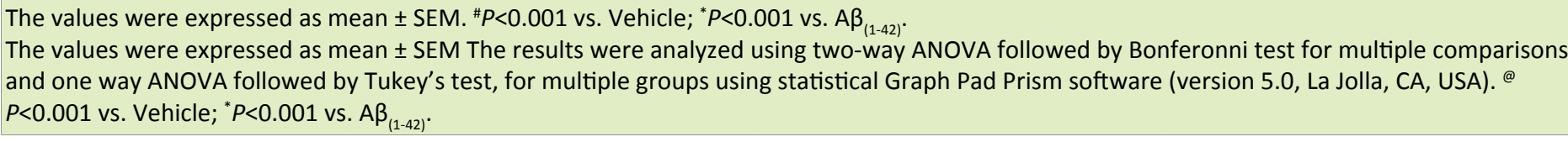 } \\
\hline
\end{tabular}


cognitive impairment which was significantly restored by lupeol treatment $[39,40]$.

Recent neuropathological studies have found that AD patients have complex neurochemical disturbances including the catecholaminergic, cholinergic neuronal systems and their restoration may improve memory in $A D[9,10]$. In addition, modulators of acetylcholine (ACh), dopamine, 5-HT and NE have also been reported to improve hippocampal dependant memory in clinical and preclinical cases of $A D$ [41-43]. $A \beta_{(1-42)}$ in both clinical and preclinical $A D$, has reports to causes catecholaminergic deficit by escalating AChE enzymatic activity $[44,45]$. In agreement with the previous findings, the present study also showed significant increase in AChE activity in $A \beta_{(1-42)}$ infused brains [6-10]. However, the treatment of lupeol was able to significantly decrease $A C h E$ activity as reported earlier [17]. The finding of the current study suggest that lupeol contributes to the restoration of ACh level by reducing the level of $A C h E$ in $A \beta_{(1-42)}$ infused rat's hippocampus. Thus, recovery in the levels of these monoamines may contribute to the beneficial effects of lupeol on learning and memory in $A \beta$ induced $A D$ in rats.

Neuroinflammation and oxidative-nitrosative stress are two most common events of $A \beta_{(1-42)}$-induced neurotoxicity and neuronal cell death as seen in AD patients [46]. Brain regions such as hippocampus and cortex are highly sensitive to oxidative stress, mitochondrial dysfunction and neuroinflammation $[47,48]$. The expansive nature of oxidative damage in AD includes mitochondrial dysfunction, $A \beta$ formation, tau aggregation and alterations in calcium signaling [48]. All these changes lead to alterations in the transcriptional activity of various pathways, over-production of MDA, and reduced activity of superoxide dismutase, catalase, and GSH [47-49]. $A \beta_{(1-42)}$ is well known oligomer to causes oxidative stress, microglia and astrocytes activation and over expression of pro-inflammatory cytokines such as IL-1 $\beta$, IL- 6 and TNF- $\alpha$. [50]. In the present study, $A \beta_{(1-42)}$ infused brain tissues exhibit an increase in oxidative stress, pro-inflammatory cytokines and nitrite level which stay in good agreement with its previous findings [51]. However, lupeol treatment significantly attenuated $A \beta_{(1-42)}$ induced oxidative-nitritive stress and decreased the levels of pro-inflammatory cytokines, confirming its antioxidant and antiinflammatory properties [52]. Earlier reports have also suggested that oral administration of lupeol decreases the secretion of pro-inflammatory cytokines such as TNF- $\alpha$, and IL-1 $\beta$ and inhibit the over activation of microglia and astrocytes [52]. It has been reported that lupeol act through various mechanism and downregulates various apoptotic molecules like Bax, cytochrome $C$ and caspases that leads to neuronal death [52]. Moreover Lupeol has also been reported to exhibit neuroprotective action against the glutamate induced exitotoxicity in mouse hippocampal cells [22]. Thus, the observed anti-inflammatory antioxidant effects of lupeol help to decrease the neuronal oxidative stress and may offer novel strategies in the treatment of age-related AD.

\section{Conclusion}

In the current study, lupeol halt $A \beta_{(1-42)}$ induced behavioral, biochemical and neurochemical abnormalities in rats. Lupeol was able to improve behavioral changes, restore neurotransmitters levels, decreased oxidative-nitrosative stress and reduced inflammatory processes. Together these findings suggest multiple therapeutic approach of lupeol towards $A \beta_{(1-42)}$ induced dementia and suggest lupeol as a potential therapeutic molecule to treat $A D$ like symptoms.

\section{Acknowledgement}

Authors are thankful to University Grant Commission (UGC), Delhi and ISF College of Pharmacy, Moga (Punjab) for valuable financial support and encouragement.

\section{Conflict of Interest}

The authors declare no competing financial interest. 


\section{References}

1 Lowe VJ, Kemp BJ, Jack CR, Senjem M, Weigand S, et al. (2009) Comparison of $18 \mathrm{~F}-\mathrm{FDG}$ and PiB PET in cognitive impairment. J Nucl Med 50: 878-886.

2 Crews L, Masliah E (2010) Molecular mechanisms of neurodegeneration in Alzheimer's disease. Hum Mol Genet ddq160.

3 Moreira PI, Carvalho C, Zhu X, Smith MA, Perry G (2010) Mitochondrial dysfunction is a trigger of Alzheimer's disease Pathophysiology. Biochim Biophys Acta Mol Basis Dis 1802: 2-10.

4 Gella A, Bolea I (2011) Oxidative stress in Alzheimer's disease: Pathogenesis, biomarkers and therapy. INTECH Open Access Publisher, Rijeka, Croatia.

5 Peixoto CA, Nunes AKS, Garcia-Osta A (2015) Phosphodiesterase-5 inhibitors: Action on the signaling pathways of neuroinflammation, neurodegeneration and cognition. Mediators Inflamm.

6 Martorana A, Koch G (2013) Is dopamine involved in Alzheimer's disease?. Front Aging Neurosci 6: 252-253.

7 Trillo L, Das D, Hsieh W, Medina B, Moghadam S, et al. (2013) Ascending monoaminergic systems alterations in Alzheimer's disease. Translating basic science into clinical care. Neurosci Biobehav Rev 37: 1363-1379.

8 Francis BM (2013) Noradrenergic deficits contribute to impairment in the TgCRND8 mouse model of Alzheimer's disease. PhD. Thesis, University of Toronto, Toronto, Canada.

9 Heii A, Yosuke I, Kenji K, Takashi M, Reiji I (1992) Neurotransmitter changes in early-and late-onset Alzheimer-type dementia. Prog Neuropsychopharmacol Biol Psychiatry 16: 883-890.

10 Kar S, Slowikowski SP, Westaway D, Mount HT (2004) Interactions between [beta]-amyloid and central cholinergic neurons: Implications for Alzheimer's disease. J Psychiatry Neurosci 29: 427-441.

11 Siddique HR, Saleem M (2011) Beneficial health effects of lupeoltriterpene: A review of preclinical studies. Life sciences 88: 285-293.

12 Reddy KP, Singh AB, Puri A, Srivastava AK, Narender T (2009) Synthesis of novel triterpenoid (lupeol) derivatives and their in vivo anti-hyperglycemic and anti-dyslipidemic activity. Bioorg Med Chem Lett 19: 4463-4466.

13 Saeed MA, Sabir AW (2002) Irritant potential of triterpenoids from Ficuscarica leaves. Fitoterapia 73: 417-420.

14 Oliveira EMS, Freitas SL, Martins FS, Couto RO, Pinto MV, et al. (2012) Isolation and quantitative HPLC-PDA analysis of lupeol in phytopharmaceutical intermediate products from Vernonanthuraferruginea (Less.) H. Rob. 'Quím. Nova 35: 1041-1045.

15 Parmar SK, Sharma TP, Airao VB, Bhatt R, Aghara R, et al. (2013) Neuropharmacological effects of triterpenoids. Phytopharmacol 4: 354-372.

16 Besbes M, Guérineau V, Touboul D (2013) Isolation and structure elucidation of acetylcholinesterase lipophilic lupeol derivatives inhibitors from the latex of the Tunisian Periplocalaevigata. Arabian J Chem.

17 Ahmad M, Weber AD, Zanon G, Tavares LDC, Ilha V, et al. (2014) Inhibitory and enzyme-kinetic Investigation of chelerythrine and lupeol Isolated from Zanthoxylumrhoifolium against krait snake venom acetylcholinesterase. J Braz Chem Soc 25: 98-103.
18 Lakshmi V, Mahdi AA, Ahmad MK, Agarwal SK, Srivastava AK (2015) Anti-diabetic activity of lupeol and lupeol esters in streptozotocininduced diabetic rats. Bangladesh Pharm J 17: 138-146.

19 Ding Y, Nguyen HT, Kim SI, Kim HW, Kim YH (2009) The regulation of inflammatory cytokine secretion in macrophage cell line by the chemical constituents of Rhussylvestris. Bioorg Med Chem Lett 19: 3607-3610.

20 He Y, Liu F, Zhang L, Wu Y, Hu B, et al. (2011) Growth inhibition and apoptosis induced by lupeol, a dietary triterpene, in human hepatocellular carcinoma cells. Biol Pharm Bull 34: 517-522.

21 Brimson JM, Brimson SJ, Brimson CA, Rakkhitawatthana $\mathrm{V}$ Tencomnao T (2012) Rhinacanthus nasutus extracts prevents glutamate and amyloid- $\beta$ neurotoxicity in HT-22 mouse hippocampal cells: possible active compounds include lupeol, stigmasterol and $\beta$-sitosterol. Int J Mol Sci 13: 5074-5097.

22 Stancu IC, Vasconcelos B, Terwel D, Dewachter I (2014) Models of beta-amyloid induced Tau-pathology: The long and 'folded'road to understand the mechanism. Mol Neurodegener 9: 51.

23 Abdullahi SM, Musa AM, Abdullahi MI, Sule MI, Sani YM (2013) Isolation of Lupeol from the Stem-bark of Lonchocarpussericeus (Papilionaceae). Sch A Cad J Biosci 1: 18-19.

24 Paxinos G, Watson C (1986) The rat brain in stereotaxic coordinates. (2nd edn). Academic Press, Sydney.

25 Chávez PA, Sandoval A, Arrieta Jesús RB, Flores AM, Navarrete A (2009) Gastroprotective effect of $\beta$-lupeol: role of prostaglandins, sulfhydryls and nitric oxide. Rev Latinoam Quím 37: 133-143.

26 Giorgetti M, Gibbons JA, Bernales S, Alfaro IE, La Rochelle CD, et al. (2010) Cognition-enhancing properties of Dimebon in a rat novel object recognition task are unlikely to be associated with acetylcholinesterase inhibition or $\mathrm{N}$-methyl-D-aspartate receptor antagonism. J Pharm Exp Ther 333: 748-757.

27 Morris R (1984) Developments of a water-maze procedure for studying spatial learning in the rat. J Neurosci Methods 11: 47-60.

28 Lowry OH, Rosebrough NJ, Farr AL, Randall RJ (1951) Protein measurement with the Folin phenol reagent. J Biol Chem 193: 265-275.

29 Ellman GL, Courtney KD, Andres V, Featherstone RM (1961) A new and rapid colorimetric determination of acetylcholinesterase activity. Biochem Pharmacol 7: 88-95.

30 Wills ED (1966) Mechanisms of lipid peroxide formation in animal tissues. Biochem J 99: 667-676.

31 Green LC, Wagner DA, Glogowski J, Skipper PL, Wishnok JS, et al. (1982) Analysis of nitrate, nitrite, and [15 N] nitrate in biological fluids. Anal Chem 126: 131-138.

32 Ellman GL (1959) Tissue sulfhydryl groups. Arch Biochem Biophys 82: 70-77.

33 Jamwal S, Singh S, Kaur N, Kumar P (2015) Protective effect of spermidine against excitotoxic neuronal death induced by quinolinic acid in rats: Possible neurotransmitters and neuroinflammatory mechanism. Neurotox Res 28: 171-184.

34 Dodart JC, May P (2005) Overview on rodent models of Alzheimer's disease. Curr Protoc Neurosci pp: 9-22.

35 Bussey TJ, Duck J, Muir JL, Aggleton JP (2000) Distinct patterns of behavioural impairments resulting from fornix transection or neurotoxic lesions of the peri-rhinal and post-rhinal cortices in the rat. Behav Brain Res 111: 187-202. 
36 D'Hooge R, De Deyn PP (2001) Applications of the Morris water maze in the study of learning and memory. Brain Res Rev 36: 60-90.

37 Murray EA, Richmond BJ (2001) Role of perirhinal cortex in object perception, memory, and associations. Curr Opin Neurobiol 11: 188193.

38 Antunes M, Biala G (2012) The novel object recognition memory: Neurobiology, test procedure, and its modifications. Cogn Process 13: 93-110.

39 Badinter F, Amit T, Bar-Am O, Youdim MB, Weinreb O, et al. (2015) Beneficial behavioral, neurochemical and molecular effects of 1-(R)aminoindan in aged mice. Neuropharmacol 99: 264-272.

40 JuárezOlguín $\mathrm{H}$, Calderón-Guzmán D, Hernández-García E, BarragánMejía G (2015) The role of dopamine and its dysfunction as a consequence of oxidative stress. Oxid Med Cell Longev.

41 Suri D, Teixeira CM, Cagliostro MKC, Mahadevia D, Ansorge MS (2015) Monoamine-sensitive developmental periods impacting adult emotional and cognitive behaviors. Neuropsychopharmacology 40: 88-112.

42 Yasuno F, Suhara T, Nakayama T, Ichimiya T, Okubo Y, et al. (2003) Inhibitory effect of hippocampal 5-HT1A receptors on human explicit memory. Am J Psychiatry 160: 334-340.

43 Praticò D, Delanty N (2000) Oxidative injury in diseases of the central nervous system: Focus on Alzheimer's disease. Am J Med 109: 577-585.

44 Wu CR, Lin HC, Su MH (2014) Reversal by aqueous extracts of Cistanche tubulosa from behavioral deficits in Alzheimer's diseaselike rat model: Relevance for amyloid deposition and central neurotransmitter function BMC complement. Altern Med 14: 1.
45 Schoffelmeer AN, Mulder $\mathrm{AH}$ (1983) 3H-Noradrenaline release from rat neocortical slices in the absence of extracellular $\mathrm{Ca} 2+$ and its presynaptic alpha2-adrenergic modulation Naunyn Schmiedebergs. Arch Pharmacol 323: 188-192.

46 Butterfield DA, Reed T, Newman SF, Sultana R (2007) Roles of amyloid $\beta$-peptide-associated oxidative stress and brain protein modifications in the pathogenesis of Alzheimer's disease and mild cognitive impairment. Free Radic Biol Med 43: 658-677.

47 Uttara B, Singh AV, Zamboni P, Mahajan RT (2009) Oxidative stress and neurodegenerative diseases: a review of upstream and downstream antioxidant therapeutic options. Current Neuropharmacol 7: 65-74.

48 Liu R, Liu IY, Bi X, Thompson RF, Doctrow SR, et al. (2003) Reversal of age-related learning deficits and brain oxidative stress in mice with superoxide dismutase/catalase mimetics. Proc Natl Acad Sci USA 100: 8526-8531.

49 Rubio-Perez JM, Morillas-Ruiz JM (2012) A review: Inflammatory process in Alzheimer's disease, role of cytokines. Scientific World J.

50 Lucetti DL, Lucetti EC, Bandeira MA, Veras HN, Silva AH, et al. (2010) Anti-inflammatory effects and possible mechanism of action of lupeol acetate isolated from Himatanthus drasticus (Mart). Plumel J Inflamm (Lond) 7: b12.

51 Badshah H, Ali T, Rehman SU, Amin FU, Ullah F, et al. (2015) Protective effect of lupeol against lipopolysaccharide-induced neuroinflammation via the p38/c-Jun $\mathrm{N}$-terminal kinase pathway in the adult mouse brain. J Neuroimmune Pharmacol 1-13

52 Kumari A, Kakkar P (2012) Lupeol prevents acetaminophen-induced in vivo hepatotoxicity by altering the $\mathrm{Bax} / \mathrm{Bcl}-2$ and oxidative stressmediated mitochondrial signaling cascade. Life Sci 90: 561-570. 